\title{
Epizootic cutaneous papillomatosis, cortisol and male ornamentation during and after breeding in the roach Rutilus rutilus
}

\author{
Anssi Vainikka ${ }^{1, *}$, Raine Kortet ${ }^{2}$, Jouni Taskinen ${ }^{3}$ \\ ${ }^{1}$ Department of Biological and Environmental Science, University of Jyväskylä, PO Box 35, University of Jyväskylä 40014, \\ Finland \\ ${ }^{2}$ Neurobiology, Physiology \& Behavior, University of California, Davis, One Shields Avenue, Davis, California 95616, USA \\ ${ }^{3}$ Institute of Applied Biotechnology, University of Kuopio, PO Box 1627, Kuopio 70211, Finland
}

\begin{abstract}
The prevalence of epidermal papillomatosis in roach is known to peak during the spawning period and to be higher in males than in females. The high occurrence of papillomatosis in polluted waters suggests that stress may contribute to the outbreak of the disease. However, little is known about breeding-induced stress in fish and its relationship with diseases. In this study, plasma cortisol concentration, hematocrit and the relative size of the spleen were determined in healthy and diseased male and female roach Rutilus rutilus during and shortly after spawning in a wild population. In addition, the sexual ornamentation (breeding tubercles on the lateral sides and on the frontal) of male roach during spawning was examined. Plasma cortisol concentration was higher during than after the spawning period, and higher in males than in females during spawning, indicating a spawning-induced stress and higher spawning stress among males. There was no correlation between cortisol concentration and the intensity of papillomatosis (number of scales under papilloma tumors) among the diseased fish. However, the significant interaction sex $\times$ disease status revealed by ANCOVA suggested that diseased males could be more prone to increased cortisol levels than diseased females or healthy males. Hematocrit values (ratio of the volume of red blood cells to total volume of blood) but not condition factor were lowered in papilloma-diseased fish after spawning. The relative size of the spleen was greater in males than in females. The number of frontal breeding tubercles correlated negatively with the intensity of papillomatosis. Experimental studies are needed to investigate the association of papillomatosis with stress and cortisol.
\end{abstract}

KEY WORDS: Breeding tubercles · Spawning stress · Gender difference $\cdot$ Hematocrit $\cdot$ Spleen

\section{INTRODUCTION}

Epidermal papillomatosis is a skin disease characterized by white, smooth, ovoid tumors on the skin, fins and lips of fishes. It has been reported in several fish species (Bylund et al. 1980, Möller \& Anders 1986, Lee \& Whitfield 1992, Mellergaard \& Nielsen 1995, Premdas et al. 1995, Kortet et al. 2002). Papillomatosis has been associated with herpesviruses in several fish species including koi carp Cyprinus carpio, smelt Osmerus eperlanus and rainbow smelt $O$. mordax (e.g. Hedrick et al. 1990, Lee \& Whitfield 1992, Sano et al. 1993, Mor- rison et al. 1996), but not all studies have been able to demonstrate an association with viruses (e.g. Lamas et al. 1990) and some have identified papillomaviruses (Edwards et al. 1977). Latent infectious agents of papillomatosis are suggested to be permanently present in the population with only a part of the population developing tumors (Lee \& Whitfield 1992, Sano et al. 1993). The disease is common in roach Rutilus rutilus populations in the current study area (Kortet et al. 2002).

Reproduction in teleosts is regulated by several sex hormones (e.g. Aida 1988, Barannikova et al. 2002) and accompanied by changes in immune functions 
(e.g. Álvarez et al. 1998, Scapigliati et al. 1999, Kortet et al. 2003a) and parasite load (e.g. Pilcher et al. 1989). In males, seasonal changes in immune functions and parasitism are suggested to result from androgen-induced immunosuppression (Folstad \& Karter 1992). In roach, the occurrence of epidermal papillomatosis is known to peak during the spawning period and to be more common in males than in females (Kortet et al. 2002). Moreover, plasma testosterone concentration is known to be higher in papilloma-infected roach males than in healthy males (Kortet et al. 2003b), although this is unlikely to explain the gender difference in the prevalence of papillomatosis, since female roach have a concentration of testosterone equal to that of males (Vainikka et al. 2004). In addition to androgen stress (Premdas et al. 2001), several physiological stress factors, such as anoxia and environmental pollutants, may cause papillomatosis to erupt in fishes (Mellergaard \& Nielsen 1995, Premdas et al. 1995). Roach spawn in shoals: males develop breeding tubercles and show territorial behavior, and females choose males to some extent (Wedekind 1996). Moreover, roach may make long migrations just before and during spawning (Mills 1991). Therefore, spawning may be a significant source of stress in roach. However, little is known about the relationship between cortisol, the most important teleost stress hormone, and the occurrence of diseases during the spawning season.

Cortisol has been shown to suppress some immune functions in fishes (Weyts et al. 1999), although it has multiple other functions in fish metabolism (Mommsen et al. 1999). Roach show a decrease in spleen size and a lowered migration activity of head-kidney phagocytes during spawning (Kortet et al. 2003a). These facts suggest that cortisol may have some role in breeding-related immunosuppression and possibly in the outbreak of epidermal papillomatosis. On the other hand, little is known about the significance of epidermal papillomatosis in fish physiology and stress state. Finding stress sources in natural conditions could help to prevent the occurrence of fish diseases, and thus facilitate better fishery management.

The aim of the present work was to study cortisol concentrations in roach during and after spawning and to examine the relationship between plasma cortisol concentration and the intensity of papillomatosis in a wild population. Sex, breeding tubercle ornamentation, hematocrit and relative spleen size were also examined to visualize papillomatosis occurrence in an evolutionary context. Roach is not a species of economic importance, but due to its generality and common use as a model species in evolutionary ecology (e.g. Kortet et al. 2003b, Vainikka et al. 2004), knowledge of its spawning and diseases is needed.

\section{MATERIALS AND METHODS}

Fish. We collected 2 samples during the roach breeding season by angling in Lake Jyväsjärvi $\left(62^{\circ} 14^{\prime} \mathrm{N}\right.$, $25^{\circ} 46^{\prime}$ E). A pre-spawning sample of 20 healthy and 20 diseased male fish and 10 healthy and 10 diseased female fish, and a post-spawning sample of 10 fish of each group were required for the study. During spawning (May 15, 2003) 65 mature, unspawned, but sexually mature specimens (Table 1) fulfilled our criteria. The second sample, comprising 36 spawned fish, was collected on May 21, 2003, 6 d after the first sample (Table 1). Fish with 1 or more tumors of at least $2 \mathrm{~mm}^{2}$ in size were regarded as infected and those with no visible signs of papillomatosis as healthy. Preliminary cursory examination in the field was followed by detailed examination in the laboratory.

After capture, the fish were immediately anesthetized using $0.1 \%$ MS-222 (Sigma Chemicals) and blood was sampled within 3 min from the caudal vein using a heparinized needle and a syringe (Heparin Leo, Leo Pharma). All fish released milt or eggs when their abdomen was mildly pressed under anesthesia. Sex was determined on the basis of breeding tubercles and gonads. All the sampled fish were examined in the order in which they were caught (practically random), and those not suitable for our study (already spawned/unripe, wrong sex, wrong papillomatosis status) were killed immediately and analyzed for the prevalence of papillomatosis (May 15) or released back into the lake (May 21). To approximate the prevalence and intensity of papillomatosis in the current study population, a total of 135 individuals (including these 65 fish used for cortisol analyses) caught randomly on May 15 by angling were examined. The fish were held in accordance with the 'Guidelines for the treatment of animals in behavioural research and teaching' (ASAB 2001) under license from the Ethical Committee for Animal Research of the University of Jyväskylä (LS32/13.05.2003).

Laboratory analyses. After blood samples had been taken, the fish were measured (total length), marked individually and placed on ice, together with blood samples, in $1.5 \mathrm{ml}$ Eppendorf tubes. In the laboratory, the hematocrit was measured by centrifuging the blood in hematocrit capillaries $(10000 \times g)$ for $5 \mathrm{~min}$. Plasma was separated by centrifuging the blood in Eppendorf tubes $(4000 \times g)$ for $10 \mathrm{~min}$ and was stored at $-72^{\circ} \mathrm{C}$ until analyzed for cortisol concentration.

After hematocrit measurement and plasma separation, the fish were dissected and their mass without intestinal organs (carcass mass) and the mass of the spleen were determined. The relative mass of the spleen (hereafter referred to as 'splenic index') was 
determined as $1000 \times$ the mass of the spleen divided by the carcass mass. Condition factor was calculated for each fish using the equation, $K=1000 \times M_{\mathrm{C}} L_{\mathrm{T}}{ }^{-b}$, where $M_{\mathrm{C}}$ is carcass mass, $L_{T}$ total length, and $b$ the slope of a regression of $\log _{10}\left(M_{\mathrm{C}}, \mathrm{g}\right)$ on $\log _{10}\left(L_{\mathrm{T}}, \mathrm{cm}\right)$. Male fish were categorized into 4 groups according to the breeding tubercle ornamentation on their lateral sides (see Taskinen \& Kortet 2002): (1) no-ornamentation; (2) very slight ornamentation; (3) clear ornamentation; (4) very rough skin and easily visible breeding tubercles. The classification of fish on the basis of their breeding-tubercle ornamentation has been shown to be highly repeatable (Kortet et al. 2003b). In addition, the number of breeding tubercles on the frontal of male roach was counted (see Kortet \& Taskinen 2004). The intensity of papillomatosis was determined by counting the number of scales covered by papillomas. The outlines of scales are visible even when covered by the largest papillomas (which were up to $2 \mathrm{~mm}$ in thickness). Moreover, the number of scales of a fish is fairly constant throughout its life-time and is thus a scalable measure of fish surface area. When papilloma were present in areas without scales, such as the fins, the area covered by the tumors was estimated as the number of scales that would be necessary to cover that area in that particular fish. Therefore, in the present study, papillomatosis intensity is given as the number of scales covered by papillomas in a diseased fish.

Determination of plasma cortisol concentration was performed in duplicate using commercial kits (Gamma-Coat, DiaSorin) based on the radioimmunoassay technique, using ${ }^{125} \mathrm{I}$ as a marker according to the manufacturer's instructions.

Statistics. The effects of sex, sampling time and disease status on the cortisol concentration, mass of the spleen and hematocrit were tested by ANCOVA using fish length as a covariate. Since post-spawning females and males lacked breeding tubercles, separate ANCOVAs for pre-spawning males were performed to analyze the effect of lateral breeding tubercle ornamentation on cortisol concentration, hematocrit, intensity of papillomatosis and mass of the spleen. Full factorial models with fixed effects were used, but only the statistically significant factors are reported. All descriptives in the results of ANCOVA have been adjusted for fish size (given by ANCOVA in the Statistical Package for Social Science (SPSS) program. Pearson's correlation analysis was used to study the relationships between plasma cortisol concentration, fish length, intensity of papillomatosis, number of breeding tubercles on the frontal of male fish, hematocrit and splenic index. A Student's $t$-test for independent samples was used to compare fish length and intensity of papillomatosis between males and females, and condition factors between healthy and diseased fish. To ful- fill the normality assumption of statistical tests (using the Kolmogorov-Smirnov test), cortisol concentration, mass of the spleen, splenic index, number of frontal breeding tubercles and number of scales under papilloma tumors were transformed using a natural logarithm. All statistical analyses were performed using SPSS for Windows 11.0.1.

\section{RESULTS}

The prevalence of papillomatosis on May 15, 2003, was $75.8 \%$ for males $(n=62$, length $178.1 \pm 14.3 \mathrm{~mm}$, mean $\pm \mathrm{SD}$ ) and $17.8 \%$ among females $(\mathrm{n}=73$, length $197.4 \pm 16.1 \mathrm{~mm}$ ). The mean intensity of papillomatosis did not differ between diseased males and females $(30.4 \pm 53.7, \mathrm{n}=47$ and $44.4 \pm 67.9, \mathrm{n}=13$, respectively, $t$-test for independent samples, $t=-0.79, \mathrm{df}=58, \mathrm{p}=$ 0.436).

Plasma cortisol concentration in the roach was significantly higher during spawning than about 1 wk after $\left(\right.$ ANCOVA $\left._{i} F_{(1,90)}=12.73, \mathrm{p}=0.001\right)(201.2 \pm 28.9$ and $66.1 \pm 38.5 \mu \mathrm{g} \mathrm{l} \mathrm{l}^{-1}$, respectively, mean $\pm \mathrm{SE}$ ). The interaction sampling time $\times$ sex was significant $\left(\mathrm{ANCOVA}_{i}\right.$ $\left.F_{(1,90)}=10.26, \mathrm{p}=0.002\right)$, indicating that the cortisol concentration in males $\left(238.5 \pm 46.8 \mu \mathrm{g} \mathrm{l}^{-1}\right)$ was higher than in females $\left(192.3 \pm 68.3 \mu \mathrm{g} \mathrm{l}^{-1}\right)$ during spawning (ANCOVA: effect of sex, $F_{(1,59)}=6.38, p=0.014$ ), while there was no difference after spawning (Fig. 1). The interaction sex $\times$ infection status $\left(\right.$ ANCOVA $_{i} F_{(1,90)}=$ $4.25, \mathrm{p}=0.042)$ indicated that diseased males had a marginally higher concentration of cortisol than healthy males, but healthy females had a marginally higher concentration of cortisol than diseased females (Fig. 1). Plasma cortisol concentration was negatively related to the length of the fish for the pooled material $\left(\right.$ ANCOVA; $\left.F_{(1,90)}=5.67, \mathrm{p}=0.019\right)$, but only for females when the sexes were analyzed separately (Pearson's $\mathrm{r}=-0.401, \mathrm{n}=39, \mathrm{p}=0.011$, for males $\mathrm{r}=$ $-0.116, n=60, p=0.377)$. Sampled females were larger than males (Table 1) (Student's $t$-test for the length; $t=$ $-9.04, \mathrm{df}=62.53, \mathrm{p}<0.001)$. The plasma cortisol concentration was not statistically significantly related to lateral breeding tubercle ornamentation of males during spawning $\left(\mathrm{ANCOVA}_{i} F_{(3,39)}=0.62, \mathrm{p}=0.605\right)$ nor to the number of frontal breeding tubercles (Pearson's $r=0.060, \mathrm{n}=44, \mathrm{p}=0.700$ ). After spawning, the breeding tubercle ornamentation of males degenerated and could not be analyzed on May 21, 2003.

The interaction disease status $\times$ time of sampling was a significant source of variation in the hematocrit values (ANCOVA $\left.; F_{(1,91)}=6.77, \mathrm{p}=0.011\right)$, and was due to the marginally higher hematocrits of papilloma-diseased fish during spawning and the marginally lower values of diseased fish after spawning compared to healthy fish 


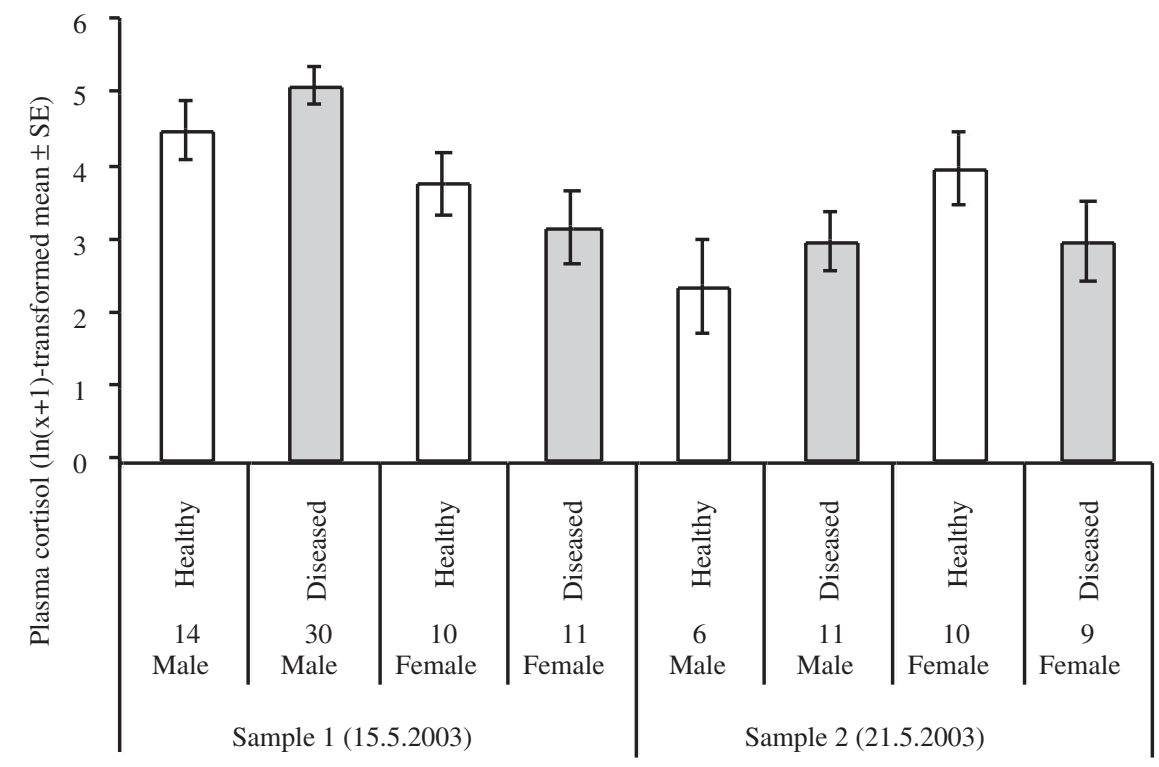

Fig. 1. Rutilus rutilus. ln $(x+1)$-transformed plasma cortisol concentration $\left(\mu \mathrm{g} \mathrm{l}^{-1}\right)$ in diseased and healthy male and female roach during (Sample 1, May 15, 2003) and after (Sample 2, May 21, 2003) spawning. Data adjusted to fish length by ANCOVA to control for effect of fish size. Untransformed values are given in 'Results'. Numbers above sex designations are number of specimens

(Fig. 2) (ANCOVA $; \mathrm{p}=0.064$ and $\mathrm{p}=0.054$, respectively). In addition, fish length was negatively related to hematocrit values (ANCOVA: covariate length, $F_{(1,91)}=6.43, \mathrm{p}$ $=0.013$, Pearson's $\mathrm{r}=-0.405, \mathrm{n}=100, \mathrm{p}<0.001)$. Condition factor did not differ between healthy and diseased post-spawning fish (Student's $t$-test, $t=0.18, \mathrm{df}=33, \mathrm{p}=$ $0.861)$. Hematocrit values were not related to male lateral breeding tubercle ornamentation during spawning (ANCOVA: ornamentation, $F_{(3,39)}=1.75, \mathrm{p}=0.173$ ) nor to the number of frontal breeding tubercles in males (Pearson's $\mathrm{r}=0.020, \mathrm{n}=44, \mathrm{p}=0.899$ ). Plasma cortisol concentration and hematocrit values were positively corre-

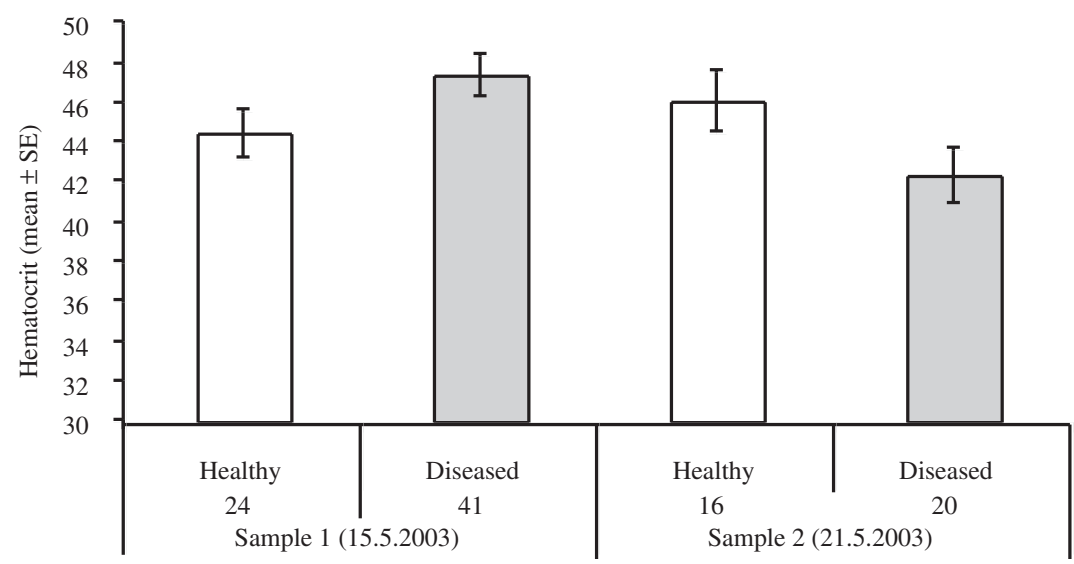

Fig. 2. Rutilus rutilus. Hematocrit values in healthy and diseased roach during (Sample 1, May 15, 2003) and after (Sample 2, May 21, 2003) spawning. Data adjusted to fish length to control for effect of fish size. Sexes pooled, since no difference between males and females lated in the pooled data (Pearson's $\mathrm{r}=0.242, \mathrm{n}=100, \mathrm{p}=$ 0.015 ), and among infected fish (Pearson's $r=0.341, \mathrm{n}=$ $60, \mathrm{p}=0.008)$.

Only fish length and sex affected splenic index (ANCOVA: covariate length, $F_{(1,91)}=75.52, \mathrm{p}<0.001$, sex, $\left.F_{(1,91)}=5.26, \mathrm{p}=0.024\right)$. The spleen was larger in males than in females (splenic index for males $=2.09 \pm$ 0.05 , for females $=1.86 \pm 0.07$, mean $\pm \mathrm{SE}$ ) and increased in size with the increasing length. The splenic index was not related to the lateral breeding tubercle ornamentation of males (ANCOVA: ornamentation, $\left.F_{(3,39)}=1.18, \mathrm{p}=0.332\right)$ during spawning, nor was it correlated with the number of frontal breeding tubercles (Pearson's $\mathrm{r}=-0.264, \mathrm{n}=41, \mathrm{p}=0.095$ ).

The intensity of papillomatosis was negatively correlated with the number of breeding tubercles on the frontal skull among males with tumors (Pearson's $\mathrm{r}=-0.406, \mathrm{n}=30, \mathrm{p}=$ 0.036). Papillomatosis intensity did not depend on lateral breeding tubercle ornamentation (among males with tumors; ANCOVA; ornamentation classification, $F_{(3,25)}=0.43, \mathrm{p}=$ 0.730 and was not correlated with hematocrit, splenic index or cortisol concentration among infected fish (Pearson's correlation analysis, $\mathrm{n}=61$, $p \geq 0.192$ ). Among infected fish, the condition factor was not related to the 
Table 1. Rutilus rutilus. Mean and SD lengths and sample sizes of roach studied

\begin{tabular}{|c|c|c|c|c|}
\hline \multirow[t]{2}{*}{ Sex } & \multirow[t]{2}{*}{ Infected } & \multirow[t]{2}{*}{$\mathrm{N}$} & \multicolumn{2}{|c|}{ Length (mm) } \\
\hline & & & Mean & $\mathrm{SD}$ \\
\hline \multicolumn{5}{|c|}{ May 15, 2003} \\
\hline \multirow[t]{2}{*}{ Male } & No & 14 & 174.1 & 13.4 \\
\hline & Yes & 30 & 181.7 & 11.9 \\
\hline \multirow[t]{2}{*}{ Female } & No & 10 & 191.6 & 14.9 \\
\hline & Yes & 11 & 216.5 & 15.8 \\
\hline \multicolumn{5}{|c|}{ May 21, 2003} \\
\hline \multirow[t]{2}{*}{ Male } & No & 6 & 173.8 & 15.6 \\
\hline & Yes & 11 & 183.5 & 6.7 \\
\hline \multirow[t]{2}{*}{ Female } & No & 10 & 208.9 & 18.8 \\
\hline & Yes & 9 & 217.9 & 8.6 \\
\hline
\end{tabular}

papillomatosis intensity, hematocrit or the splenic index (Pearson's correlation analysis; $p \geq 0.089$ ), but was negatively associated with plasma cortisol concentration (Pearson's $\mathrm{r}=-0.267, \mathrm{n}=60, \mathrm{p}=0.039$ ).

\section{DISCUSSION}

The present study recorded plasma cortisol concentrations at spawning that were nearly 20 times higher than those previously reported for unstressed roach outside the breeding period (see Pottinger et al. 1999); and a rapid, statistically significant decrease of roach plasma cortisol concentrations to one-third of the spawning-time values $6 \mathrm{~d}$ after spawning. These results suggest that roach are subject to severe stress during spawning. Furthermore, the stress may be stronger in males, as suggested by 1.25 times higher cortisol levels in males during spawning than in females. As the prevalence and intensity of papillomatosis have been observed to peak during spawning and to be higher in males than among females (Kortet et al. 2002) then, based on the above results, a relationship between cortisol and papillomatosis seems likely, e.g. as a result of cortisol-induced immunosuppression (e.g. Weyts et al. 1999, Davis et al. 2003). However, to determine the role of cortisol in papilloma development in fish requires temporal studies to determine if levels are significantly higher in specimens prior to development of papillomas than in specimens that do not evolve papillomas. Also, experimental manipulation of concentrations of fish plasma cortisol without other stress sources would be necessary to separate the effects of cortisol from the effects of other stress factors.

The insignificant correlation between plasma cortisol concentration and the intensity of papillomatosis among diseased fish suggests that visible papillomas are not the most harmful effects of this disease, i.e. the relationship between stress and tumor is not direct. Sano et al. (1993) found Herpesvirus cyprini in the cranial nerve ganglia and spinal nerves of carp Cyprinus carpio, suggesting that papillomatosis may also have non-visible internal effects on fish. However, the results of another study (Kortet et al. 2003c) indicated that papillomatosis does not significantly affect the survival of roach.

The cortisol concentration could not have been affected by the sampling procedure in our study, because all fish were handled in the same manner (anesthetized with an overdose of MS-222 and their blood sampled within 3 min of capture). The plasma cortisol concentration of fish is known to increase in $<1 \mathrm{~h}$ due to handling (Rottlant \& Tort 1997), but any increase during a $\leq 3$ min handling period under anesthesia would probably be minor (Rottlant \& Tort 1997). Angling was presumed to be the most rapid way to sample the fish, as it enabled the fish to be caught and released into the water containing the anesthetic within a few seconds.

Reproduction in teleosts is accompanied by changes in the concentrations of sex hormones (e.g. Aida 1988) and immune functions (e.g. Álvarez et al. 1998, Scapigliati et al. 1999, Kortet et al. 2003a). Earlier studies emphasized the significance of testosterone on the development of papillomatosis in fishes (Premdas et al. 2001, Kortet et al. 2003b). Thus, in roach, hormonal changes associated with reproduction, such as an increase in testosterone (Vainikka et al. 2004), could partly contribute to the development of papillomas in both sexes. However, as males and females have an equal concentration of testosterone all year round (Vainikka et al. 2004), this is unlikely to explain the observed higher prevalence of papillomatosis in males. However, this pattern might result from oxygenation of testosterone to immunosuppressive 11-ketotestosterone in males (Watanuki et al. 2002). Our results indicate the relationship between plasma cortisol and papillomatosis to be gender-dependent, as supported by the statistically significant interaction of sex $\times$ disease status (ANCOVA).

During spawning, male roach are engaged in territorial behavior, aggressive behaviors towards other males and courtship behaviors directed at females (Diamond 1985, Wedekind 1996). This may contribute to the higher cortisol concentration and stronger spawning stress in males than in females, as observed in the present study. Males also develop secondary sexual ornaments, breeding tubercles, during the breeding season (Wiley \& Collette 1970). The tubercles are keratinbased nodules which are induced by male androgens and detach shortly after spawning (Wiley \& Collette 1970, Kortet et al. 2003b). The positive relationship be- 
tween testosterone, elaborate breeding tubercle ornamentation and papillomatosis was demonstrated by Kortet et al. (2003b). The present results indicate that cortisol may have a role in the interplay between androgens, ornamentation and papillomatosis, as plasma cortisol concentration was associated with the disease status and sex of roach, and the number of frontal breeding tubercles was negatively correlated with the intensity of papillomatosis in males. There was no sign of a relationship between papillomatosis and a general measure of immune response in fishes, spleen size. The spleen is involved in hematopoiesis, the clearance of pathogens and other foreign particles from the blood stream and antibody-production (Manning 1994, Dalmo et al. 1997), and a large spleen is thought to indicate good condition and the ability to respond to infection (Wester et al. 1994). However, spleen size alone cannot be used as a measure of immunocompetence, since a large spleen size can also be an indication of infection.

The hematocrit values of papilloma-diseased fish were significantly lower after spawning than during spawning. As the hematocrit ratio has been used as an indicator of health (e.g. Munkittrick \& Leatherland 1983, Kortet et al. 2003a), this result suggested that epidermal papillomatosis might have a physiological cost and lead to lower condition in diseased fish. However, this was not supported by the comparable condition factors of healthy and diseased fish after spawning or by the positive correlation between hematocrit ratio and plasma cortisol concentration. Other factors contributing to the low hematocrit values of papillomainfected fish could include co-occurring parasites or direct effects of papilloma-causing viruses.

As hypothesized, plasma cortisol concentration seemed to peak during spawning (concurrent with the highest prevalence of epidermal papillomatosis) in roach. The observed higher concentration of plasma cortisol in males than in females may contribute to the high prevalence of papillomatosis in males during breeding, although sex hormones probably play a contributory role. However, from these results it is impossible to determine whether high cortisol concentration in diseased males is due to papillomatosis, or whether papillomatosis has been caused by acute stress. Contrary to expectation, the papillomatosis intensity was not correlated with plasma cortisol concentration among the diseased fish, indicating that any relationship between cortisol and papillomatosis is not reflected in the severity of the visible disease. Experimental studies on the effects of stress on papillomatosis induction, such as cortisol-mediation, energetic trade-offs or toxic effects, are needed to elucidate the mechanisms that underlie the outbreak of papillomatosis during stress.
Acknowledgements. The study was conducted in the Biological Interactions Graduate School of the Finnish Ministry of Education (AV). We thank the Maj and Tor Nessling Foundation for a grant to J.T. For helpful comments on the manuscript we thank R. Jones.

\section{LITERATURE CITED}

Aida M (1988) A review of plasma hormone changes during ovulation in cyprinid fishes. Aquaculture 74:11-21

Álvarez F, Razquin BE, Villena AJ, Zapata AG (1998) Seasonal changes in the lymphoid organs of wild brown trout, Salmo trutta L: a morphometrical study. Vet Immunol Immunopathol 64:267-278

ASAB (2001) Guidelines for the treatment of animals in behavioural research and teaching. Anim Behav 61: 271-275

Barannikova IA, Dyubin VP, Bayunova LV, Semenkova TB (2002) Steroids in the control of reproductive function in fish. Neurosci Behav Physiol 32:141-148

Bylund G, Valtonen, ET, Niemelä E (1980) Observations on epidermal papillomata in wild and cultured Atlantic salmon Salmo salar L. in Finland. J Fish Dis 3:525-528

Dalmo RA, Ingebritsen K, Bøgwald J (1997) Non-specific defence mechanism in fish, with particular reference to the reticuloendothelial system (RES). J Fish Dis 20: 241-273

Davis KB, Griffin BR, Gray WL (2003) Effect of dietary cortisol on resistance of channel catfish to infection by Ichthyophthirius multifiliis and channel catfish virus disease. Aquaculture 218:121-130

Diamond M (1985) Some observations of spawning by roach, Rutilus rutilus L., and bream, Abramis brama L., and their implications for management. Aquacult Fish Manag 16: 359-367

Edwards MR, Samsonoff WA, Kuzia EJ (1977) Papilloma-like viruses from catfish. Fish Health News 6:94-95

Folstad I, Karter AJ (1992) Parasites, bright males, and the immunocompetence handicap. Am Nat 139:603-622

Hedrick RP, Groff JM, Okihiro MS, McDowell TS (1990) Herpesviruses detected in papillomatous skin growths of koi carp (Cyprinus carpio). J Wildl Dis 26:578-581

Kortet R, Taskinen J (2004) Parasitism, condition and number of frontal breeding tubercles in roach (Rutilus rutilus L.) Ecol Freshw Fish (in press)

Kortet R, Vainikka A, Taskinen J (2002) Epizootic cutaneous papillomatosis in roach Rutilus rutilus: sex and size dependence, seasonal occurrence and between-population differences. Dis Aquat Org 52:185-190

Kortet R, Taskinen J, Sinisalo T, Jokinen I (2003a) Breedingrelated seasonal changes in immunocompetence, health state and condition of the cyprinid fish, Rutilus rutilus, L. Biol J Linn Soc 78:117-127

Kortet R, Vainikka A, Rantala MJ, Jokinen I, Taskinen J (2003b) Sexual ornamentation, androgens and papillomatosis in male roach (Rutilus rutilus). Evol Ecol Res 5: 411-419

Kortet R, Vainikka A, Taskinen J (2003c) Experimental study on the effect of epidermic papillomatosis on survival of the freshwater fish Rutilus rutilus. Dis Aquat Org 57:163-165

Lamas J, Anadon R, Devesa S, Toranzo AE (1990) Visceral neoplasia and epidermal papillomas in cultured turbot Scophthalmus maximus. Dis Aquat Org 8:179-187

Lee S, Whitfield PJ (1992) Virus-associated spawning papillomatosis in smelt, Osmerus eperlanus L., in the River Thames. J Fish Biol 40:503-510 
Manning MJ (1994) Fishes. In: Turner RJ (ed) Immunology: a comparative approach. John Wiley, Chichester, p 69-100

Mellergaard S, Nielsen E (1995) Impact of oxygen deficiency on the disease status of common dab Limanda limanda. Dis Aquat Org 22:101-114

Mills CA (1991) Reproduction and life history. In: Winfield IJ, Nelson S (eds) Cyprinid fishes: systematics, biology and exploitation. Chapman \& Hall, London, p 483-508

Möller H, Anders K (1986) Diseases and parasites of marine fishes, tumors and tumor-like lesions. Verlag Möller, Kiel

Mommsen TP, Vijayan MM, Moon TW (1999) Cortisol in teleosts: dynamics, mechanisms of action, and metabolic regulation. Rev Fish Biol Fish 9:211-268

Morrison CM, Leggiadro CT, Martell DJ (1996) Visualization of viruses in tumors of rainbow smelt Osmerus mordax. Dis Aquat Org 26:19-23

Munkittrick KR, Leatherland JF (1983) Haematocrit values in feral goldfish, Carassius auratus L., as indicators of the health of the population. J Fish Biol 23:153-161

Pilcher MW, Whitfield PJ, Riley JD (1989) Seasonal and regional infestation characteristics of three ectoparasites of whiting, Merlangius merlangus L., in the North Sea. J Fish Biol 35:97-110

Pottinger TG, Yeomans WE, Carrick TR (1999) Plasma cortisol and $17 \beta$-oestradiol levels in roach exposed to acute and chronic stress. J Fish Biol 54:525-532

Premdas PD, Metcalfe TL, Bailey ME, Metcalfe CD (1995) The prevalence and histological appearance of lip papillomas in white suckers from two sites in Central Ontario, Canada. J Gt Lakes Res 21:207-218

Premdas PD, Metcalfe CD, Brown S (2001) The effects of 17 $\beta$ oestradiol, testosterone and tamoxifen on the development of papillomata in Catostomus commersoni. J Fish Biol 59:1056-1069

Editorial responsibility: Jo-Ann Leong,

Kaneohe, Hawaii, USA
Rottlant J, Tort L (1997) Cortisol and glucose responses after acute stress by net handling in the sparid red porgy previously subjected to crowding stress. J Fish Biol 51:21-28

Sano N, Moriwake M, Hondo R, Sano T (1993) Herpesvirus cyprini: a search for viral genome in infected fish by in situ hybridization. J Fish Dis 16:495-499

Scapigliati G, Scalia D, Marras A, Meloni S, Mazzini M (1999) Immunoglobulin levels in the teleost sea bass Dicentrarchus labrax (L.) in relation to age, season, and water oxygenation. Aquaculture 174:207-212

Taskinen J, Kortet R (2002) Dead and alive parasites: sexual ornaments signal resistance in the male fish, Rutilus rutilus. Evol Ecol Res 4:919-929

Vainikka A, Jokinen EI, Kortet R, Taskinen J (2004) Genderand season-dependent relationships between testosterone, oestradiol and immune functions in wild roach Rutilus rutilus L. J Fish Biol 64:227-240

Watanuki H, Yamaguchi T, Sakai M (2002) Suppression in function of phagocytic cells in common carp Cyprinus carpio L. injected with estradiol, progestrone or 11ketotestosterone. Comp Biochem Physiol C 132:407-413

Wedekind C (1996) Lek-like spawning behaviour and different female mate preferences in roach (Rutilus rutilus). Behaviour 133:681-695

Wester PW, Vethaak AD, van Muiswinkelm WB (1994) Fish as biomarkers in immunotoxicology. Toxicology 86: 213-232

Weyts FAA, Cohen N, Flik G, Verburg-van Kemenade BMK (1999) Interactions between the immune system and the hypothalamo-pituitary-interrenal axis in fish. Fish Shellfish Immunol 9:1-20

Wiley ML, Collette BB (1970) Breeding tubercles and contact organs in fishes: their occurrence, structure and significance. Bull Am Mus Nat Hist 143:145-216

Submitted: November 3, 2003; Accepted: April 27, 2004

Proofs received from author(s): August 2, 2004 